\title{
Inhaled Nitric Oxide at Birth Reduces Pulmonary Vascular Resistance and Improves Oxygenation in Preterm Lambs
}

\author{
Satyan Lakshminrusimha ${ }^{1, *(\mathbb{D})}$, Sylvia F. Gugino ${ }^{2,3}$, Krishnamurthy Sekar ${ }^{4}$, Stephen Wedgwood ${ }^{1}$, \\ Carmon Koenigsknecht ${ }^{2}$, Jayasree Nair ${ }^{2}$ (D) and Bobby Mathew ${ }^{2}$ \\ 1 Departments of Pediatrics, University of California at Davis, UC Davis Children's Hospital, \\ 2516 Stockton Blvd, Sacramento, CA 95817, USA; swedgwood@ucdavis.edu \\ 2 Department of Pediatrics, State University of New York at Buffalo, Buffalo, NY 14222, USA; \\ sfgugino@buffalo.edu (S.F.G.); carmonko@buffalo.edu (C.K.); jnair@upa.chob.edu (J.N.); \\ bmathew@upa.chob.edu (B.M.) \\ 3 Physiology and Biophysics, State University of New York at Buffalo, Buffalo, NY 14222, USA \\ 4 Department of Pediatrics, University of Oklahoma, Oklahoma City, OK 73013, USA; \\ Krishnamurthy-Sekar@ouhsc.edu \\ * Correspondence: slakshmi@ucdavis.edu; Tel.: +1-(916)-734-5178
}

check for updates

Citation: Lakshminrusimha, S.; Gugino, S.F.; Sekar, K.; Wedgwood, S.; Koenigsknecht, C.; Nair, J.; Mathew, B. Inhaled Nitric Oxide at Birth Reduces Pulmonary Vascular Resistance and Improves Oxygenation in Preterm Lambs. Children 2021, 8, 378. https:// doi.org/10.3390/children8050378

Academic Editor:

Bernhard Schwaberger

Received: 16 April 2021

Accepted: 5 May 2021

Published: 11 May 2021

Publisher's Note: MDPI stays neutral with regard to jurisdictional claims in published maps and institutional affiliations.

Copyright: (c) 2021 by the authors. Licensee MDPI, Basel, Switzerland. This article is an open access article distributed under the terms and conditions of the Creative Commons Attribution (CC BY) license (https:// creativecommons.org/licenses/by/ $4.0 /)$.

\begin{abstract}
Resuscitation with $21 \% \mathrm{O}_{2}$ may not achieve target oxygenation in preterm infants and in neonates with persistent pulmonary hypertension of the newborn (PPHN). Inhaled nitric oxide (iNO) at birth can reduce pulmonary vascular resistance (PVR) and improve $\mathrm{PaO}_{2}$. We studied the effect of iNO on oxygenation and changes in PVR in preterm lambs with and without PPHN during resuscitation and stabilization at birth. Preterm lambs with and without PPHN (induced by antenatal ductal ligation) were delivered at $134 \mathrm{~d}$ gestation (term is $147-150 \mathrm{~d}$ ). Lambs without PPHN were ventilated with $21 \% \mathrm{O}_{2}$, titrated $\mathrm{O}_{2}$ to maintain target oxygenation or $21 \% \mathrm{O}_{2}+\mathrm{iNO}(20 \mathrm{ppm})$ at birth for $30 \mathrm{~min}$. Preterm lambs with PPHN were ventilated with $50 \% \mathrm{O}_{2}$, titrated $\mathrm{O}_{2}$ or $50 \% \mathrm{O}_{2}+$ iNO. Resuscitation with $21 \% \mathrm{O}_{2}$ in preterm lambs and $50 \% \mathrm{O}_{2}$ in PPHN lambs did not achieve target oxygenation. Inhaled NO significantly decreased PVR in all lambs and increased $\mathrm{PaO}_{2}$ in preterm lambs ventilated with $21 \% \mathrm{O}_{2}$ similar to that achieved by titrated $\mathrm{O}_{2}(41 \pm 9 \%$ at $30 \mathrm{~min})$. Inhaled NO increased $\mathrm{PaO}_{2}$ to $45 \pm 13,45 \pm 20$ and $76 \pm 11 \mathrm{mmHg}$ with $50 \% \mathrm{O}_{2}$, titrated $\mathrm{O}_{2}$ up to $100 \%$ and $50 \% \mathrm{O}_{2}+\mathrm{iNO}$, respectively, in PPHN lambs. We concluded that iNO at birth reduces $\mathrm{PVR}$ and $\mathrm{FiO}_{2}$ required to achieve target $\mathrm{PaO}_{2}$.
\end{abstract}

Keywords: inhaled nitric oxide; resuscitation; prematurity; persistent pulmonary hypertension of newborn; pulmonary vascular resistance; hypoxic pulmonary vasoconstriction

\section{Introduction}

During fetal life, pulmonary vascular resistance (PVR) is high and $\mathrm{PaO}_{2}$ levels are low compared to the postnatal period [1]. Oxygen is a potent and specific pulmonary vasodilator and plays an important role in decreasing PVR at birth [1]. After birth, PVR gradually decreases and oxygenation slowly improves over the first minutes of life. Current neonatal resuscitation guidelines recommend the use of $21 \%$ oxygen in the delivery room resuscitation of term infants [2]. However, controversy exists as to the optimal resuscitation gas in preterm infants [3]. Recent studies suggest that extremely preterm infants who were first resuscitated with $21 \%$ oxygen and titrated up to achieve target $\mathrm{SpO}_{2}$ had higher mortality from respiratory failure compared to infants whose resuscitation was initiated with $100 \%$ oxygen and titrated down [4]. However, high initial inspired oxygen concentration ( $>65 \%)$ is not recommended during resuscitation of preterm infants due to the risk of oxidative stress $[5,6]$. Promoting pulmonary vasodilation without excessive supplemental oxygen can potentially facilitate the establishment of gas exchange in the lung without exposing the infant to oxygen toxicity. 
Persistent pulmonary hypertension of the newborn (PPHN) [7] is a disorder characterized by elevated pulmonary vascular resistance (PVR), extra-pulmonary right-to-left shunting and hypoxemia. Inhaled nitric oxide (iNO) is a selective pulmonary vasodilator approved by the Food and Drug Administration in term infants with PPHN and acts by increasing cGMP in pulmonary arterial smooth muscle cells (PASMC). We hypothesized that ventilation with iNO at birth would reduce PVR and increase arterial partial pressure of oxygen both in preterm newborn lambs and in PPHN lambs, similar to that achieved by high $\mathrm{FiO}_{2}$ (Figure 1). Our overall aim was to evaluate if iNO supplementation resulted in a reduced need for inspired oxygen as being secondary to a decrease in PVR in animal models with and without PPHN.

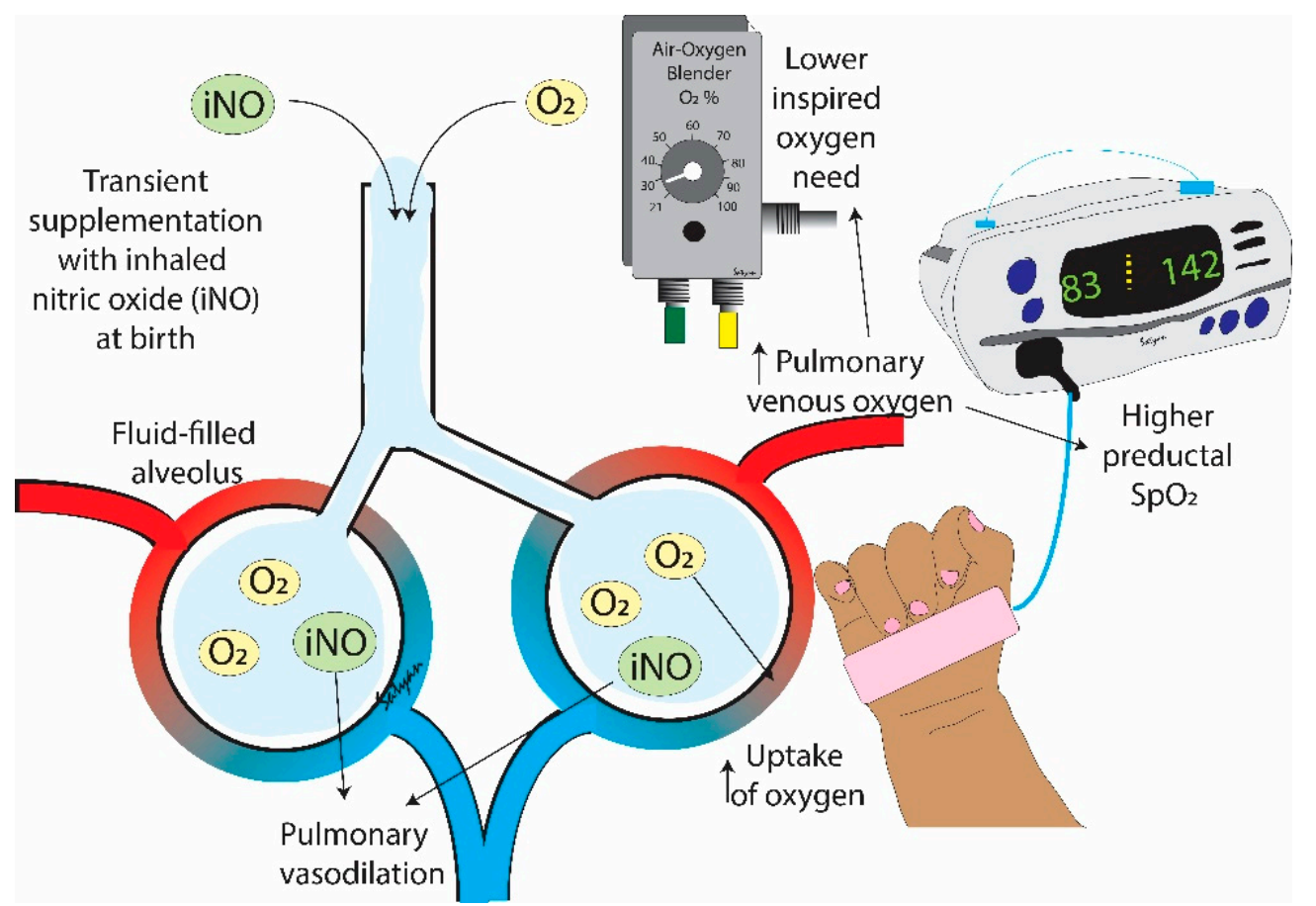

Figure 1. Hypothesis. Newly born, preterm infants have immature lungs filled with liquid. Administration of low concentrations of inspired oxygen alone may not be adequate to achieve target oxygen saturation $\left(\mathrm{SpO}_{2}\right)$. Transient supplementation with inhaled nitric oxide (iNO) during delivery room resuscitation and stabilization can promote pulmonary vasodilation and enhance gas exchange leading to a lower need for inspired oxygen and higher preductal $\mathrm{SpO}_{2}$. Copyright Satyan Lakshminrusimha.

\section{Materials and Methods}

This study was approved by the University at Buffalo Institutional Animal Care and Use Committee. Time-dated pregnant ewes were procured from New Pasteur farms, Attica, NY. Lambs were delivered by caesarean section at $134 \mathrm{~d}$ gestation (term gestation in lambs is 147-150 days). We used the ovine in utero ductal ligation model to induce PPHN. Time-dated pregnant ewes were anesthetized as previously described [8] and fetal ductus arteriosus was ligated at $128 \mathrm{~d}$ gestational age [9]. The fetus was then placed back in the uterus for 8 days. On the day of delivery, preterm lambs (with and without PPHN) were partially exteriorized by cesarean section and catheters were placed in the jugular vein and carotid artery to obtain $\mathrm{PaO}_{2}$ measurements at different levels of oxygen exposure with and without iNO. The dose of iNO was $20 \mathrm{ppm}$. We conducted the study in 2 phases: 
I. Oxygenation studies: Preterm lambs with and without PPHN were intubated at birth and randomized to be ventilated with 21,50 or $100 \%$ oxygen with or without iNO for $30 \mathrm{~min}$. Preductal arterial gases were drawn every $5 \mathrm{~min}$ and recorded.

II. Pulmonary hemodynamic studies: In a subsequent set of experiments, we studied the effect of iNO on oxygenation and pulmonary vascular resistance. These lambs were exteriorized as described previously [8,9]. In addition to the placement of right carotid and jugular lines, we performed a thoracotomy and placed pulmonary arterial and left atrial catheters to measure pressures and a pulmonary arterial flow probe to measure blood flow. The flow probe was placed around the left pulmonary artery in lambs without PPHN to avoid the influence of blood flow through the patent ductus arteriosus (PDA). In lambs with PPHN, the flow probe was placed around the main pulmonary artery as the ductus arteriosus was ligated in utero to induce PPHN.

a. Based on results from phase I oxygenation studies, preterm lambs without PPHN were exposed to $21 \%$ oxygen, titrated oxygen to maintain $\mathrm{PaO}_{2}$ between 45 and $80 \mathrm{mmHg}$ and titrated oxygen with iNO at $20 \mathrm{ppm}$.

b. In lambs with PPHN, $21 \%$ oxygen was avoided as $\mathrm{PaO}_{2}$ levels were low with this $\mathrm{FiO}_{2}$ in phase I oxygenation studies. PPHN lambs were exposed to $50 \%$ oxygen, titrated oxygen to maintain $\mathrm{PaO}_{2}$ between 45 and $80 \mathrm{mmHg}$ and titrated oxygen with iNO at $20 \mathrm{ppm}$ for $30 \mathrm{~min}$.

c. Lambs were effectively anesthetized during the period of instrumentation through the isoflurane inhalant administered to the ewe. The lambs were then delivered and ventilated at the following initial settings: $30 \mathrm{~cm} \mathrm{H}_{2} \mathrm{O}$ peak inspiratory pressure, $5 \mathrm{~cm} \mathrm{H}_{2} \mathrm{O}$ positive end expiratory pressure, and 40 respirations per minute. Sedation was maintained by administration of an initial propofol bolus $(2 \mathrm{mg} / \mathrm{kg}$ ) followed by a constant rate infusion given to effect. Additional doses of fentanyl at $1-5 \mathrm{mcg} / \mathrm{kg}$ were administered as needed for signs of discomfort. Maintenance IV fluid with dextrose and electrolytes was also provided. Arterial blood pressure, heart rate, and pulse oximetry were monitored and recorded. Ventilator settings were adjusted to maintain a $\mathrm{PaCO}_{2}$ between 35 and $50 \mathrm{mmHg}$.

d. Pulmonary vascular resistance was calculated as follows:

$\mathrm{PVR}=($ mean PA pressure - LA pressure $) /$ pulmonary blood flow in $\left(\mathrm{mL} \cdot \mathrm{min}^{-1} \cdot \mathrm{kg}^{-1}\right)$

In lambs without PPHN, the left pulmonary arterial flow was used to calculate the "left" PVR. In lambs with PPHN, the main pulmonary arterial flow was used for this calculation.

\section{Results}

I. Oxygenation studies: Thirty-six preterm lambs without PPHN and 30 lambs with PPHN were included in this phase of the study (6 lambs in each group). There was a significant difference in birth weight between preterm lambs without PPHN $(3059 \pm 105 \mathrm{~g})$ and lambs with PPHN $(2576 \pm 210 \mathrm{~g})$. The birth weights, gender distribution, and multiplicity were similar between the iNO and no-iNO groups (data not shown). Fetal blood gases were similar between preterm lambs with and without PPHN $\left(\mathrm{PaO}_{2}-18.4 \pm 7.2\right.$ and $17.5 \pm 6.1 \mathrm{mmHg}$ respectively $)$ and between lambs ventilated with and without iNO (Figure 2).

a. Preterm lambs without PPHN ventilated with $21 \%$ oxygen gradually increased their $\mathrm{PaO}_{2}$ over the first $30 \mathrm{~min}$. Ventilation with iNO significantly increased $\mathrm{PaO}_{2}$ at 5 ( $39 \pm 3$ vs. $56 \pm 11 \mathrm{mmHg}$ ) and $10 \mathrm{~min}(43 \pm 3$ vs. $63 \pm 12 \mathrm{mmHg})$. There was no difference in $\mathrm{PaO}_{2}$ with and without iNO by 30 min (Figure 2Ai). Ventilation with 50 and $100 \%$ oxygen significantly increased $\mathrm{PaO}_{2}$ compared to $21 \%$ oxygen reaching supraphysiological levels by $5 \mathrm{~min}$. However, addition of iNO did not increase $\mathrm{PaO}_{2}$ when preterm lambs were ventilated with 50 and $100 \%$ oxygen (Figure $2 \mathrm{~A}$ ). 
b. Preterm lambs with PPHN had low $\mathrm{PaO}_{2}$ values compared to lambs without PPHN (Figure 2). Ventilation with 21\% oxygen resulted in low $\mathrm{PaO}_{2}$ values (30 $\pm 6 \mathrm{mmHg}$ at $30 \mathrm{~min}$ ). Increasing inspired oxygen from 21 to $50 \%$ significantly increased $\mathrm{PaO}_{2}$ in lambs with PPHN (45 $\pm 13 \mathrm{mmHg}$ at $30 \mathrm{~min}$ with $50 \%$ oxygen). However, further increase in inspired oxygen from 50 to $100 \%$ did not further increase $\mathrm{PaO}_{2}(44.5 \pm 20 \mathrm{mmHg}$ at $30 \mathrm{~min}$ with $100 \%$ oxygen). Inhaled nitric oxide significantly increased $\mathrm{PaO}_{2}$ with 21,50 and $100 \%$ oxygen in lambs with PPHN. Three PPHN lambs were hydropic (one each in $21 \%$ oxygen, $21 \%$ oxygen $+\mathrm{iNO}$, and $50 \%$ oxygen groups) with massive pleural effusions and ascites and were excluded, reducing the number of lambs in these groups to five.

II. Hemodynamic studies: Fifteen preterm lambs without PPHN and 15 lambs with PPHN underwent thoracotomy and placement of pressure and flow probes to measure PVR.

a. Preterm lambs without PPHN were divided into three groups. The first group was ventilated with $21 \% \mathrm{O}_{2}(n=5)$. A steady decline in PVR was measured with ventilation. The second group received titrated inspired oxygen adjusted every 5 min to maintain a $\mathrm{PaO}_{2}$ between 45 and $80 \mathrm{mmHg}(n=5)$. This required increase in inspired oxygen to $41 \pm 9 \%$ by $30 \mathrm{~min}$. The decline in PVR in this group was similar to the $21 \%$ oxygen group. The third group received iNO at 20 ppm and inspired oxygen was titrated to maintain $\mathrm{PaO}_{2}$ between 45 and $80 \mathrm{mmHg}(n=5)$. This group needed $21 \%$ oxygen throughout the $30 \mathrm{~min}$ period. The $\mathrm{PaO}_{2}$ and PVR with $21 \%$ oxygen + iNO was significantly lower than the previous two groups (Figure 3A,B). The preductal $\mathrm{SpO}_{2}$ value at 5 min was $66 \pm 8,63 \pm 9$ and $89 \pm 11 \%$ in $21 \% \mathrm{O}_{2}$, titrated $\mathrm{O}_{2}$ and $21 \% \mathrm{O}_{2}+\mathrm{iNO}$ groups respectively. The corresponding values at $30 \mathrm{~min}$ were $86 \pm 11,87 \pm 10$ and $85 \pm 13 \%$.

b. Preterm lambs with PPHN were also divided into 3 groups. The first was ventilated with 50\% oxygen $(n=5)$. There was a modest decrease in PVR and increase in $\mathrm{PaO}_{2}$ but some PPHN lambs remained hypoxemic with $\mathrm{PaO}_{2}<45 \mathrm{mmHg}$ (Figure 4). The second group received titrated inspired oxygen starting at 50\% and adjusted to maintain $\mathrm{PaO}_{2}$ between 45 and $80 \mathrm{mmHg}(n=5)$. By $10 \mathrm{~min}$, all lambs in this group were on $100 \% \mathrm{O}_{2}$. The reduction in PVR and increase in $\mathrm{PaO}_{2}$ in this group was similar to the $50 \%$ oxygen group in spite of the significantly higher inspired oxygen. The third group was initially ventilated with $50 \%$ oxygen with iNO 20 ppm $(n=5)$. The PVR in this group was significantly lower and $\mathrm{PaO}_{2}$ significantly higher than the other two. By $30 \mathrm{~min}$, inspired oxygen could be weaned to $44 \pm 2 \%$ (Figure 4). The preductal $\mathrm{SpO}_{2}$ value at $5 \mathrm{~min}$ was $33 \pm 14,61 \pm 11$ and $71 \pm 13 \%$ in $50 \% \mathrm{O}_{2}$, titrated $\mathrm{O}_{2}$ and $50 \% \mathrm{O}_{2}+\mathrm{iNO}$ groups respectively. The corresponding values at $30 \mathrm{~min}$ were $78 \pm 13,80 \pm 14$ and $92 \pm 8 \%$. 

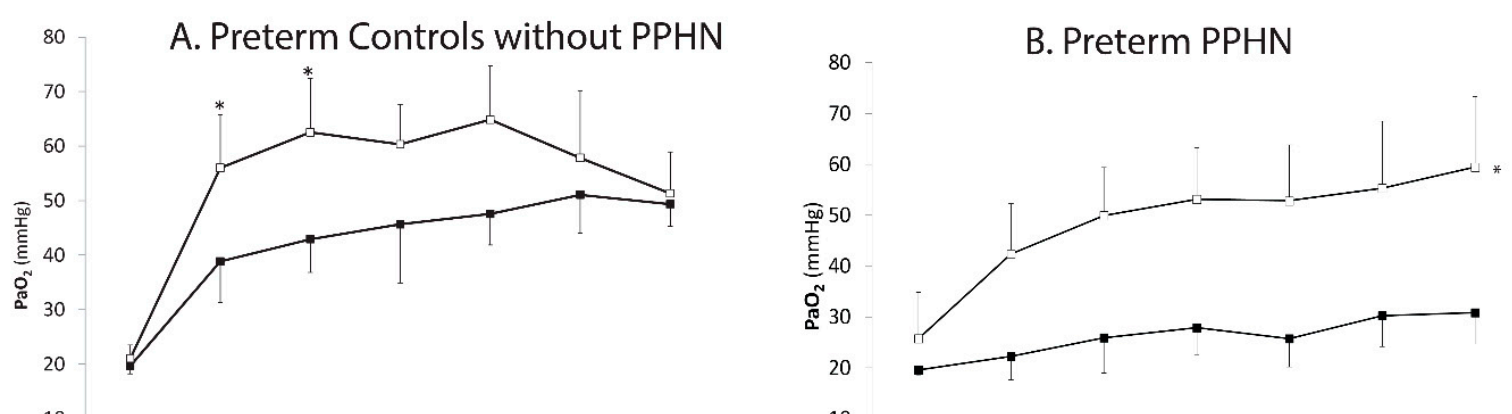

(i) $21 \%$ Oxygen

(i) $21 \%$ Oxygen

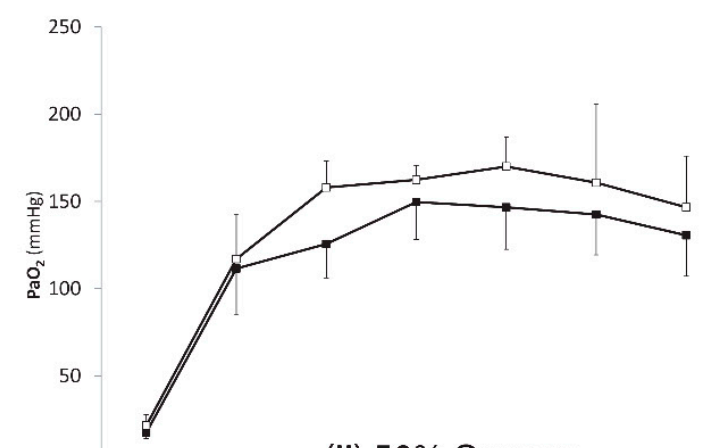

(ii) $50 \%$ Oxygen

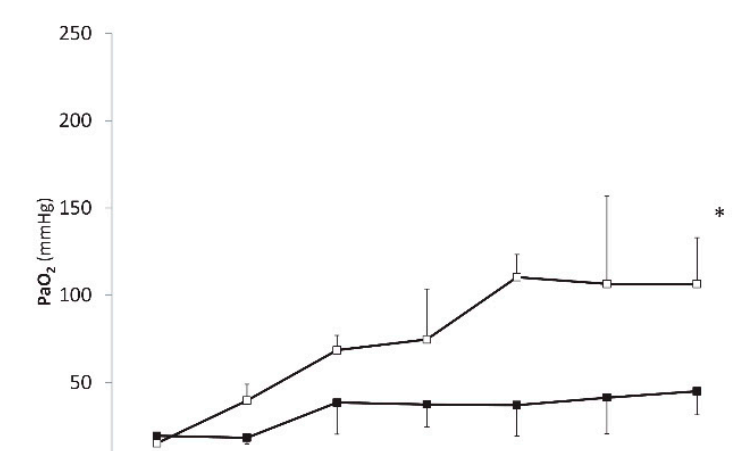

(ii) 50\% Oxygen
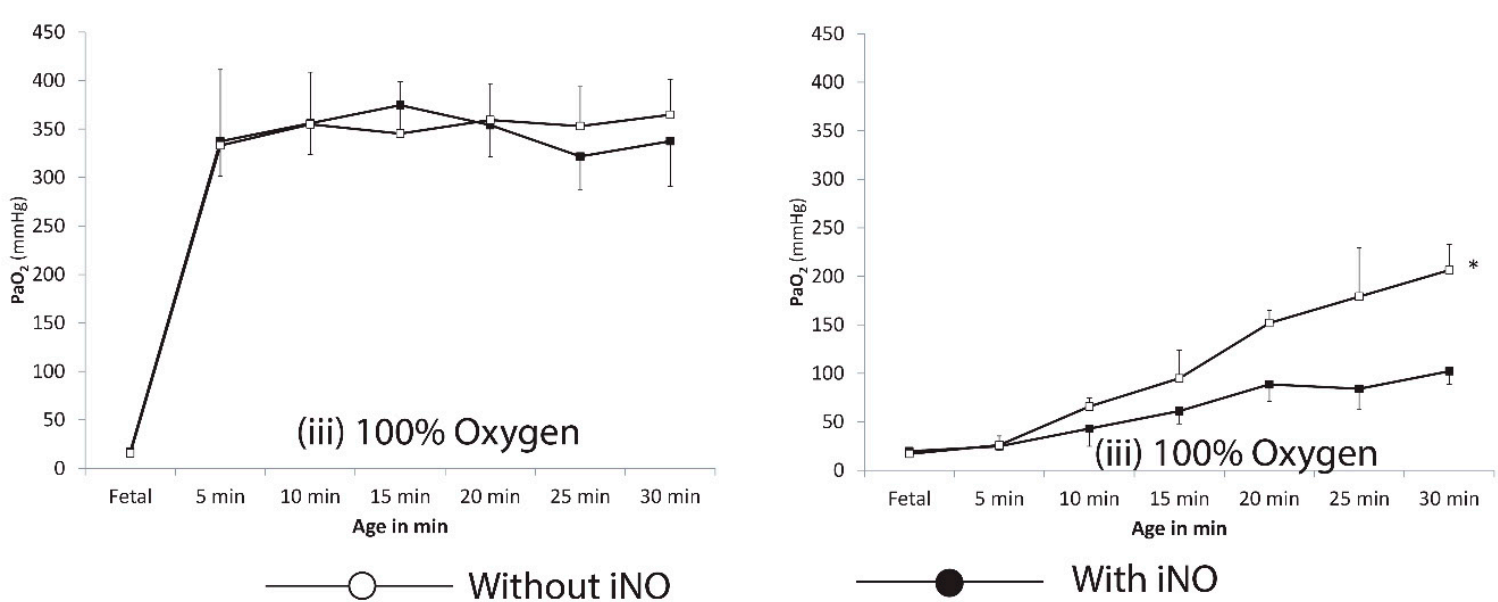

Figure 2. Changes in oxygenation with inhaled nitric oxide (iNO): $\mathrm{PaO}_{2}$ in the first 30 min of life in (A) preterm lambs without persistent pulmonary hypertension of the newborn (PPHN) with exposure to 21, 50 and 100\% oxygen with (open squares) and without iNO at 20 ppm (solid squares). (B) $\mathrm{PaO}_{2}$ in the first $30 \mathrm{~min}$ of life in preterm lambs with PPHN on exposure to 21,50 and $100 \%$ oxygen with (open squares)and without iNO (solid squares) at $20 \mathrm{ppm}$. ${ }^{*} p<0.05$ compared to $\mathrm{PaO}_{2}$ without iNO. 

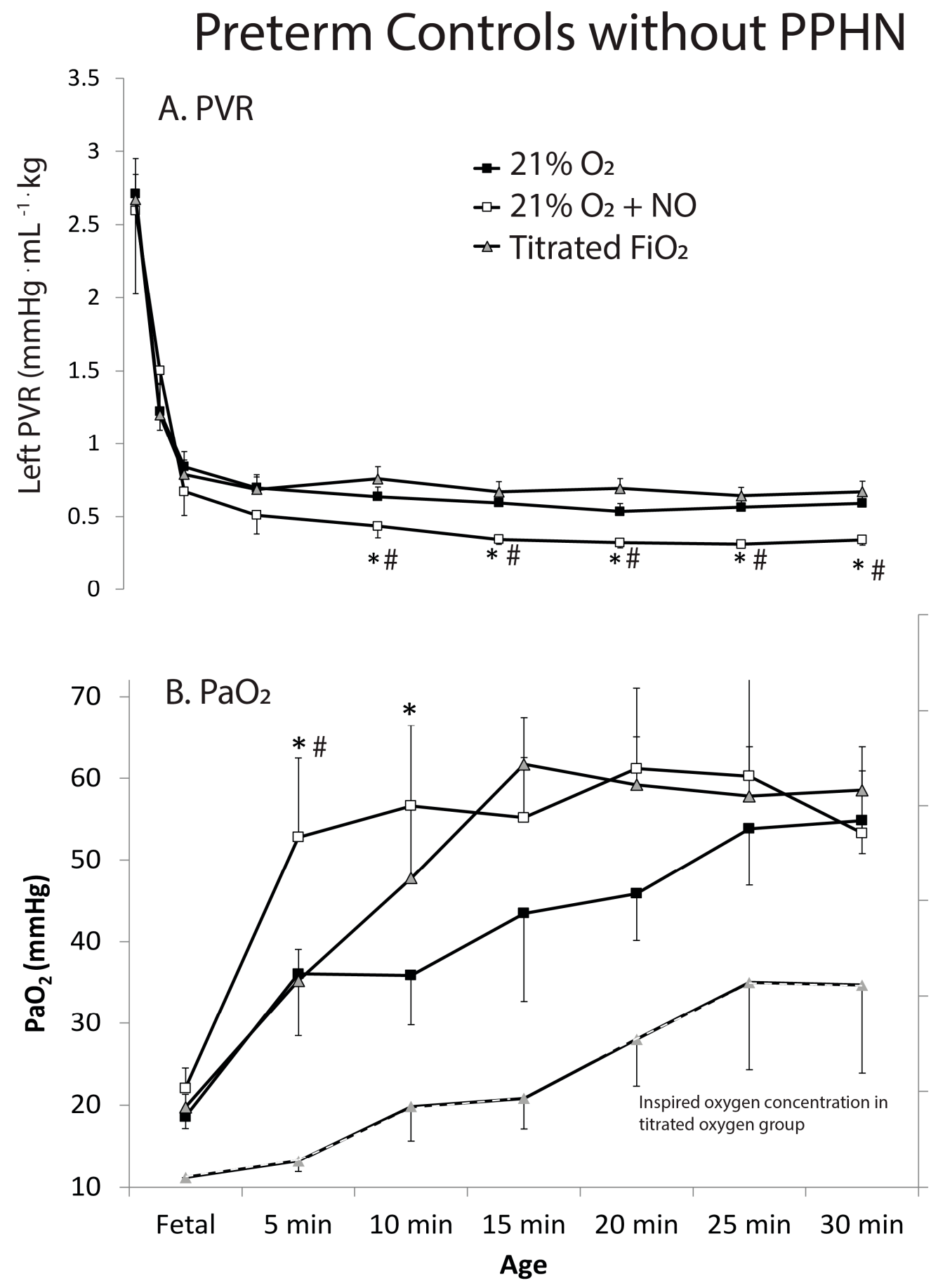

Figure 3. Changes in Pulmonary vascular resistance (PVR) in left lung (A) and $\mathrm{PaO}_{2}$ (B) in preterm lambs exposed to $21 \%$ oxygen (solid squares) vs. $21 \%$ oxygen and iNO (open squares) and titrated oxygen (gray triangles). Inspired oxygen concentration needed in the titrated oxygen group to maintain $\mathrm{PaO}_{2}$ between 45 to $80 \mathrm{mmHg}$ is shown by a hyphenated line on the secondary $y$-axis (gray triangles). ${ }^{*} p<0.05$ compared to $21 \%$ oxygen group; $\# p<0.05$ compared to titrated oxygen group. 


\section{Preterm PPHN}
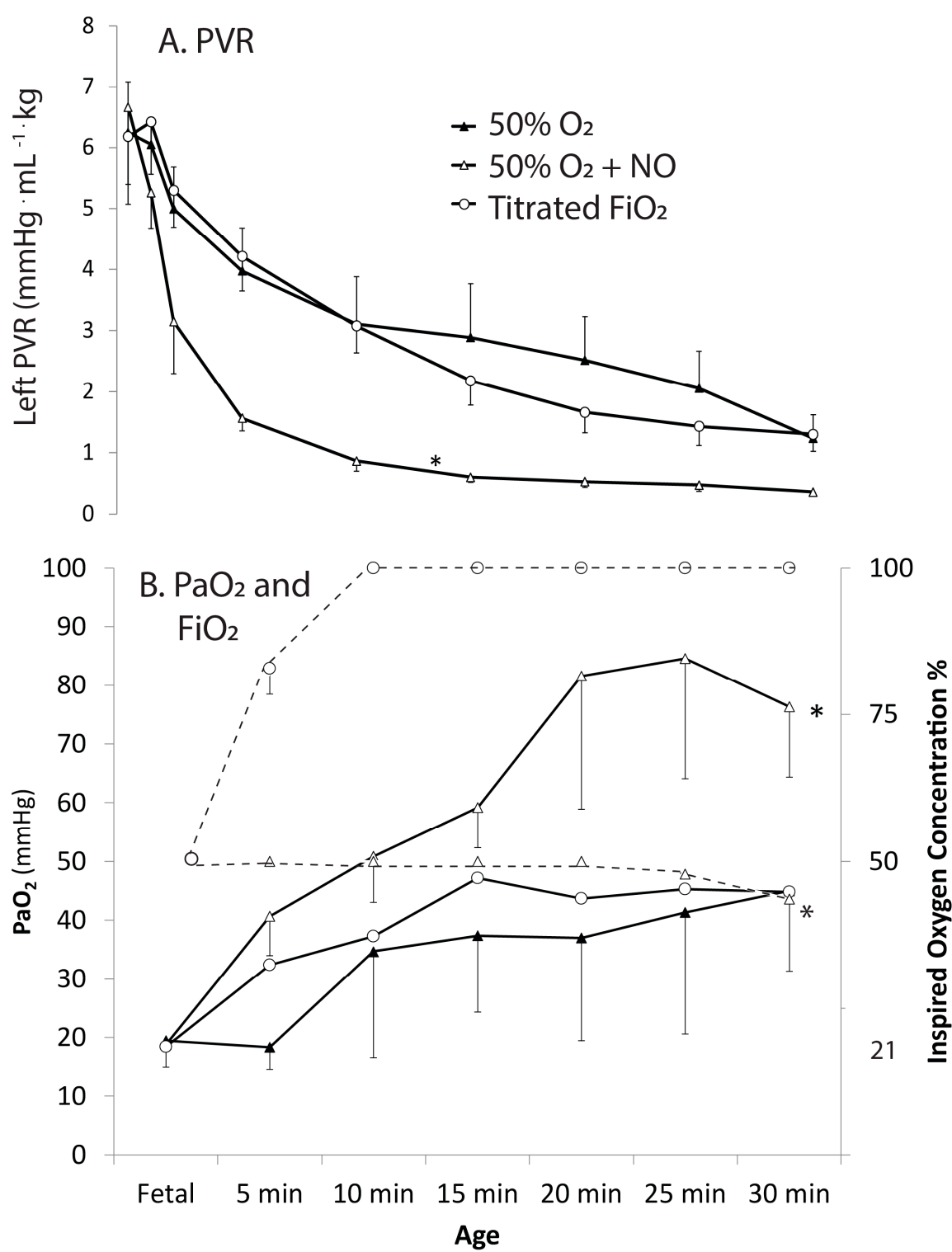

Figure 4. Changes in total pulmonary vascular resistance (PVR) in both lungs (A) and $\mathrm{PaO}_{2}(\mathbf{B})$ in PPHN lambs exposed to $50 \%$ oxygen (solid triangles) vs initiation with $50 \%$ oxygen and iNO and titration (open triangles) and titrated oxygen (open circles). Inspired oxygen concentration in the titrated oxygen group (open circles) and titrated oxygen with iNO (open triangles) is represented by a hyphenated line ${ }^{*} p<0.05$ compared to corresponding value without iNO.

\section{Discussion}

In the current study, we demonstrated that supplementation with iNO during resuscitation at birth in preterm lambs with and without PPHN reduced PVR and inspired oxygen concentration necessary to achieve target $\mathrm{PaO}_{2}$ levels. These findings have implications for delivery room resuscitation of preterm infants [10-12] and infants with PPHN [13].

The main goal of neonatal resuscitation is to achieve adequate ventilation of the lung and establishment of lung as the organ of gas exchange [5]. While $21 \%$ oxygen is effective for resuscitating term infants, the optimal oxygen concentration for resuscitation of preterm infants continues to be controversial [14], resulting in variations in clinical practice guidelines [15]. A comparison of low oxygen (initial oxygen concentration 21-30\%) and high oxygen (60-100\%) strategies has not demonstrated improvement in long-term outcomes in 
preterm infants. [3] Low-oxygen strategies are associated with reduced oxidative stress [16] and improved pulmonary outcomes in some studies [17]. However, not achieving a saturation of $80 \%$ by $5 \mathrm{~min}$ of postnatal age (whether due to inadequate oxygen supplementation or pulmonary or pulmonary vascular disease) is associated with adverse outcomes [12] One approach to improving systemic oxygenation and promoting pulmonary vasodilation during transition at birth, while establishing the lung as the organ of gas exchange without excessive supplemental oxygen, is to use a selective pulmonary vasodilator such as iNO in the delivery room. In a recently published pilot double-blind randomized controlled trial on the use of inhaled nitric oxide in the delivery room resuscitation of extremely low birthweight preterm infants by Sekar et al., those who received 20 ppm iNO as an adjuvant in the resuscitation gas had a lower cumulative $\mathrm{FiO}_{2}$ exposure and a lower rate of exposure to $\mathrm{FiO}_{2}>0.6$ [18].

Inhaled $\mathrm{NO}$ improved $\mathrm{PaO}_{2}$, and reduced the need for supplemental oxygen from $41 \pm 9$ to $21 \%$ in preterm lambs. PVR significantly decreased with the use of $21 \%$ oxygen with iNO. Studies in extremely preterm infants have suggested increased mortality in infants resuscitated in $21 \%[4,19]$ Although the physiological basis of the increased mortality is not fully understood, one plausible explanation is that infants who were resuscitated in $21 \%$ oxygen were exposed to hypoxia and inadequate pulmonary vasodilation in the immediate newborn period. Our study demonstrated improved oxygenation by 5 min and improved pulmonary vasodilation with the use of iNO at birth in preterm lambs.

During fetal life, adequate oxygen delivery is achieved by an umbilical venous $\mathrm{pO}_{2}$ of 32-35 mmHg [20], and fetal PVR is high with physiologic pulmonary hypertension [21]. However, in the immediate postnatal period, similar $\mathrm{PaO}_{2}$ values resulted in hypoxic pulmonary vasoconstriction [22]. Achieving a preductal $\mathrm{PaO}_{2}$ of $45 \mathrm{mmHg}$ (equivalent to $80 \% \mathrm{SpO}_{2}$ ) by $5 \mathrm{~min}$ [12] is an important goal and can be achieved with lower supplemental oxygen if iNO is started at birth in preterm infants (Figure 1). This $\mathrm{PaO}_{2}$ of $45 \mathrm{mmHg}$ is also the change point below which hypoxic pulmonary vasoconstriction was observed in newborn calves [22] and lambs [8,23]. Interestingly, the improvement in $\mathrm{PaO}_{2}$ in preterm lambs with iNO was observed only in the $21 \%$ oxygen group, not in the 50 and $100 \%$ groups. We speculate that the increase in alveolar oxygen $\left(\mathrm{PAO}_{2}\right)$ and supraphysiological arterial oxygenation $\left(\mathrm{PaO}_{2}\right)$ achieved with 50 and $100 \%$ inspired oxygen in preterm lambs induced pulmonary vasodilation and the addition of iNO did not result in further pulmonary vasodilation. The administration of $21 \%$ oxygen with iNO results in low PVR with the benefit of avoiding hypoxia without increasing the risk of hyperoxia.

In the lambs with PPHN, resuscitation with supplemental oxygen alone (including $100 \%$ oxygen) did not achieve optimal $\mathrm{PaO}_{2}$ levels by 5 and $10 \mathrm{~min}$ of postnatal age. Inhaled NO improves oxygenation at all levels of inspired oxygen (21, 50 and 100\%). The use of iNO in the delivery room in infants with suspected PPHN may not be practical. In most cases, with the exception of congenital diaphragmatic hernia $(\mathrm{CDH}), \mathrm{PPHN}$ is not diagnosed in the delivery room. In infants with $\mathrm{CDH}$, iNO has not been effective in reducing the need for ECMO [24], and initial resuscitation with 50\% oxygen is feasible and not associated with adverse events [13].

Preterm neonates have deficient antioxidant systems and are susceptible to oxygen toxicity [25]. Increased oxygen tension in the blood and tissues increases the risk of oxygen toxicity [26] by the formation of reactive oxygen species exceeding the antioxidant capability of the neonate [27]. The optimal inspired oxygen concentration should deliver an adequate amount of oxygen to the tissues at the lowest possible oxygen tension.

The use of high concentrations of oxygen or iNO at birth can have both short-term and long-term negative consequences. High concentration of oxygen during the resuscitation of an asphyxiated neonate can increase superoxide anions, [28] peroxynitrite and isoprostanes $[9,29]$. A combination of iNO and oxygen may have other unknown side effects (including potential epigenetic changes) [30,31]. The use of iNO in preterm infants with hypoxemic respiratory failure and pulmonary hypertension is controversial. [32-35] When used with high concentrations of oxygen, iNO can increase nitrosative stress. [9] 
Using iNO adds a significant risk of generating toxic nitrosative derivatives such as nitrotyrosine, nitro-albumin and highly toxic perioynitrite. Nitric oxide scavenges superoxide anions by competing with superoxide dismutase. Superoxide anions are generated during the fetal-to-neonatal transition, especially when supplemental oxygen is provided [28]. Sequestration of superoxide by NO may lead to an apparent reduction in oxidative stress markers. [9] Simultaneous evaluation of nitrosative stress markers should be performed to avoid drawing erroneous conclusions. Inhaled NO use in the NICU has been associated with increased childhood malignancies [31,36]. Vento and Sanchez-Illana in a comment to the Sekar et al. trial recommend a long-term neurodevelopmental follow-up among preterm neonates exposed to iNO at birth [37].

There are several limitations to the current study. All preterm lambs were intubated during resuscitation. The effectiveness of iNO when administered through non-invasive ventilation in the delivery room is not known. However, in the pilot trial by Sekar et al., iNO was effective in reducing $\mathrm{FiO}_{2}$ during resuscitation in the delivery room [18]. We monitored pulse oximetry but mainly relied on frequent preductal $\mathrm{PaO}_{2}$ measurements for titrating inspired oxygen due to the variable relationship between $\mathrm{SpO}_{2}$ and $\mathrm{PaO}_{2}$ [38]. Such titration is not feasible in a clinical situation. Given the high concentration of fetal hemoglobin at birth, reliance on $\mathrm{PaO}_{2}$ may result higher risk of hyperoxemia compared to titration using $\mathrm{SpO}_{2}$. Preterm lambs were at 134 days gestation which corresponded approximately to late preterm infants at approximately 34 weeks gestation in late saccular stage. Lambs at 80 to 120 days of gestation corresponded to 17-27 weeks of human gestation and were in the canalicular stage of lung development [39]. This maturity at 134 days was older than the gestation of infants in the Sekar et al. trial (25-31 weeks) [18]. The ductal ligation model of PPHN did not have parenchymal lung disease. The results of this study may not be applicable to PPHN secondary to parenchymal diseases such as respiratory distress syndrome, meconium aspiration syndrome and pneumonia. Inhaled NO improved oxygenation in neonatal models of atelectasis [40], but its effectiveness in preventing hypoxic pulmonary vasoconstriction in such models is not known. It is possible that lower doses of iNO $(<20 \mathrm{ppm})$ or other inhaled pulmonary vasodilators such as prostacyclin analogs may show similar results [41]. Presence of respiratory or metabolic acidosis may modify the lamb's response to hypoxia. We did not study the effect of $\mathrm{pH}$ and asphyxiation at birth on oxygenation and response to iNO [22,42]. There are substantial differences between animal models and controlled translational studies and human neonates in a hectic clinical setting. Recent studies have shown stark differences in the outcomes of translational and clinical studies, such as sustained inflation in preterm infants at birth [43]. Lastly, we did not measure oxidative or nitrosative stress.

\section{Conclusions}

We concluded that iNO is effective for improving oxygenation in both preterm lambs and lambs with PPHN without increasing inspired oxygen. Inhaled NO reduced PVR in the immediate newborn period in preterm neonatal lambs with normal lungs and with PPHN. A randomized controlled masked pilot study evaluating the use of iNO in preterm infants showed a reduced $\mathrm{FiO}_{2}$ requirement with iNO use. Larger randomized studies with long-term follow-up and studies evaluating oxidative and nitrosative stress following short uses of iNO are warranted. The limited available information on the use of iNO in the delivery room precludes its use in neonatal resuscitation except in well-controlled trials.

Author Contributions: Conceptualization, S.L., K.S. and B.M.; Data curation, S.F.G. and J.N.; Methodology, S.L., S.F.G., S.W., C.K. and J.N.; Project administration, S.F.G.; Writing-original draft, S.L. and B.M.; Writing-review and editing, S.W., C.K. and J.N. All authors will be informed about each step of manuscript processing including submission, revision, revision reminders via emails from our system or the assigned assistant editor. All authors have read and agreed to the published version of the manuscript. 
Funding: Funded by NIH 1 R01 HD072929 (SL); Inhaled nitric oxide was provided by Ikaria LLC, Hampton NJ, USA through an equipment grant. (currently Mallinckrodt Pharmaceuticals, Bedminster, NJ, USA).

Institutional Review Board Statement: This study was approved by the University at Buffalo Institutional Animal Care and Use Committee.

Data Availability Statement: Data provided on request.

Conflicts of Interest: S.L. was a speaker for Ikaria LLC from July 2011 to October 2014; Ikaria had no role in designing the study or analysis of the results or writing the manuscript.

\section{References}

1. Lakshminrusimha, S.; Steinhorn, R.H. Pulmonary vascular biology during neonatal transition. Clin. Perinatol. 1999, 26, 601-619. [CrossRef]

2. Wyckoff, M.H.; Wyllie, J.; Aziz, K.; de Almeida, M.F.; Fabres, J.; Fawke, J.; Guinsburg, R.; Hosono, S.; Isayama, T.; Kapadia, V.S.; et al. Neonatal Life Support: 2020 International Consensus on Cardiopulmonary Resuscitation and Emergency Cardiovascular Care Science With Treatment Recommendations. Circulation 2020, 142, S185-S221. [CrossRef] [PubMed]

3. Welsford, M.; Nishiyama, C.; Shortt, C.; Weiner, G.; Roehr, C.C.; Isayama, T.; Dawson, J.A.; Wyckoff, M.H.; Rabi, Y.; International Liaison Committee on Resuscitation Neonatal Life Support Task Force. Initial Oxygen Use for Preterm Newborn Resuscitation: A Systematic Review With Meta-analysis. Pediatrics 2019, 143. [CrossRef] [PubMed]

4. Oei, J.L.; Saugstad, O.D.; Lui, K.; Wright, I.M.; Smyth, J.P.; Craven, P.; Wang, Y.A.; McMullan, R.; Coates, E.; Ward, M.; et al. Targeted Oxygen in the Resuscitation of Preterm Infants, a Randomized Clinical Trial. Pediatrics 2017, 139. [CrossRef]

5. Wyckoff, M.H.; Aziz, K.; Escobedo, M.B.; Kapadia, V.S.; Kattwinkel, J.; Perlman, J.M.; Simon, W.M.; Weiner, G.M.; Zaichkin, J.G. Part 13: Neonatal Resuscitation: 2015 American Heart Association Guidelines Update for Cardiopulmonary Resuscitation and Emergency Cardiovascular Care (Reprint). Pediatrics 2015. [CrossRef] [PubMed]

6. Perlman, J.M.; Wyllie, J.; Kattwinkel, J.; Wyckoff, M.H.; Aziz, K.; Guinsburg, R.; Kim, H.S.; Liley, H.G.; Mildenhall, L.; Simon, W.M.; et al. Part 7: Neonatal Resuscitation: 2015 International Consensus on Cardiopulmonary Resuscitation and Emergency Cardiovascular Care Science With Treatment Recommendations (Reprint). Pediatrics 2015. [CrossRef]

7. Lakshminrusimha, S. Neonatal and Postneonatal Pulmonary Hypertension. Children 2021, 8, 131. [CrossRef]

8. Lakshminrusimha, S.; Swartz, D.D.; Gugino, S.F.; Ma, C.X.; Wynn, K.A.; Ryan, R.M.; Russell, J.A.; Steinhorn, R.H. Oxygen concentration and pulmonary hemodynamics in newborn lambs with pulmonary hypertension. Pediatric Res. 2009, 66, 539-544. [CrossRef]

9. Lakshminrusimha, S.; Russell, J.A.; Wedgwood, S.; Gugino, S.F.; Kazzaz, J.A.; Davis, J.M.; Steinhorn, R.H. Superoxide dismutase improves oxygenation and reduces oxidation in neonatal pulmonary hypertension. Am. J. Respir. Crit. Care Med. 2006, 174, 1370-1377. [CrossRef]

10. Kapadia, V.; Rabi, Y.; Oei, J.L. The Goldilocks principle. Oxygen in the delivery room: When is it too little, too much, and just right? Semin. Fetal Neonatal Med. 2018, 23, 347-354. [CrossRef] [PubMed]

11. Kapadia, V.; Wyckoff, M.H. Oxygen Therapy in the Delivery Room: What Is the Right Dose? Clin. Perinatol. 2018, 45, 293-306. [CrossRef]

12. Oei, J.L.; Finer, N.N.; Saugstad, O.D.; Wright, I.M.; Rabi, Y.; Tarnow-Mordi, W.; Rich, W.; Kapadia, V.; Rook, D.; Smyth, J.P.; et al. Outcomes of oxygen saturation targeting during delivery room stabilisation of preterm infants. Arch. Dis. Child. Fetal Neonatal Ed. 2018, 103, F446-F454. [CrossRef]

13. Riley, J.S.; Antiel, R.M.; Rintoul, N.E.; Ades, A.M.; Waqar, L.N.; Lin, N.; Herkert, L.M.; D'Agostino, J.A.; Hoffman, C.; Peranteau, W.H.; et al. Reduced oxygen concentration for the resuscitation of infants with congenital diaphragmatic hernia. J. Perinatol. 2018, 38, 834-843. [CrossRef]

14. Torres-Cuevas, I.; Cernada, M.; Nunez, A.; Escobar, J.; Kuligowski, J.; Chafer-Pericas, C.; Vento, M. Oxygen Supplementation to Stabilize Preterm Infants in the Fetal to Neonatal Transition: No Satisfactory Answer. Front. Pediatr. 2016, 4, 29. [CrossRef] [PubMed]

15. Wilson, A.; Vento, M.; Shah, P.S.; Saugstad, O.; Finer, N.; Rich, W.; Morton, R.L.; Rabi, Y.; Tarnow-Mordi, W.; Suzuki, K.; et al. A review of international clinical practice guidelines for the use of oxygen in the delivery room resuscitation of preterm infants. Acta Paediatr. 2018, 107, 20-27. [CrossRef] [PubMed]

16. Saugstad, O.D.; Lakshminrusimha, S.; Vento, M. Optimizing Oxygenation of the Extremely Premature Infant during the First Few Minutes of Life: Start Low or High? J. Pediatrics 2020. [CrossRef]

17. Kapadia, V.S.; Chalak, L.F.; Sparks, J.E.; Allen, J.R.; Savani, R.C.; Wyckoff, M.H. Resuscitation of Preterm Neonates With Limited Versus High Oxygen Strategy. Pediatrics 2013. [CrossRef]

18. Sekar, K.; Szyld, E.; McCoy, M.; Wlodaver, A.; Dannaway, D.; Helmbrecht, A.; Riley, J.; Manfredo, A.; Anderson, M.; Lakshminrusimha, S.; et al. Inhaled nitric oxide as an adjunct to neonatal resuscitation in premature infants: A pilot, double blind, randomized controlled trial. Pediatric Res. 2020, 87, 523-528. [CrossRef] [PubMed] 
19. Rabi, Y.; Lodha, A.; Soraisham, A.; Singhal, N.; Barrington, K.; Shah, P.S. Outcomes of preterm infants following the introduction of room air resuscitation. Resuscitation 2015, 96, 252-259. [CrossRef]

20. Rudolph, A.M. Congenital Diseases of the Heart: Clinical-Physiological Considerations, 3rd ed.; John Wiley and Sons Ltd.: West Sussex, UK, 2009.

21. Vali, P.; Lakshminrusimha, S. The Fetus Can Teach Us: Oxygen and the Pulmonary Vasculature. Children 2017, 4, 67. [CrossRef]

22. Rudolph, A.M.; Yuan, S. Response of the pulmonary vasculature to hypoxia and $\mathrm{H}+$ ion concentration changes. J. Clin. Investig. 1966, 45, 399-411. [CrossRef] [PubMed]

23. Lakshminrusimha, S.; Konduri, G.G.; Steinhorn, R.H. Considerations in the management of hypoxemic respiratory failure and persistent pulmonary hypertension in term and late preterm neonates. J. Perinatol. Off. J. Calif. Perinat. Assoc. 2016, 36 (Suppl. 2), S12-S19. [CrossRef] [PubMed]

24. The Neonatal Inhaled Nitric Oxide Study Group, N. Inhaled nitric oxide and hypoxic respiratory failure in infants with congenital diaphragmatic hernia. The Neonatal Inhaled Nitric Oxide Study Group (NINOS). Pediatrics 1997, 99, 838-845.

25. Auten, R.L.; Davis, J.M. Oxygen toxicity and reactive oxygen species: The devil is in the details. Pediatr. Res. 2009, 66, 121-127. [CrossRef] [PubMed]

26. Richmond, S.; Goldsmith, J.P. Air or 100\% oxygen in neonatal resuscitation? Clin. Perinatol. 2006, 33, 11-27. [CrossRef] [PubMed]

27. Buonocore, G.; Perrone, S.; Tataranno, M.L. Oxygen toxicity: Chemistry and biology of reactive oxygen species. Semin. Fetal Neonatal Med. 2010, 15, 186-190. [CrossRef]

28. Solberg, R.; Andresen, J.H.; Escrig, R.; Vento, M.; Saugstad, O.D. Resuscitation of hypoxic newborn piglets with oxygen induces a dose-dependent increase in markers of oxidation. Pediatr. Res. 2007, 62, 559-563. [CrossRef]

29. Lakshminrusimha, S.; Russell, J.A.; Steinhorn, R.H.; Ryan, R.M.; Gugino, S.F.; Morin, F.C., 3rd; Swartz, D.D.; Kumar, V.H. Pulmonary arterial contractility in neonatal lambs increases with $100 \%$ oxygen resuscitation. Pediatr. Res. 2006, 59, 137-141. [CrossRef]

30. Lorente-Pozo, S.; Parra-Llorca, A.; Lara-Canton, I.; Solaz, A.; Garcia-Jimenez, J.L.; Pallardo, F.V.; Vento, M. Oxygen in the neonatal period: Oxidative stress, oxygen load and epigenetic changes. Semin. Fetal Neonatal Med. 2020, 25, 101090. [CrossRef]

31. Vali, P.; Vento, M.; Underwood, M.; Lakshminrusimha, S. Free radical damage can cause serious long-lasting effects. Acta Paediatr. 2018. [CrossRef]

32. Kumar, P. Use of inhaled nitric oxide in preterm infants. Pediatrics 2014, 133, 164-170. [CrossRef] [PubMed]

33. Finer, N.N.; Evans, N. Inhaled nitric oxide for the preterm infant: Evidence versus practice. Pediatrics 2015, 135, 754-756. [CrossRef] [PubMed]

34. Ellsworth, K.R.; Ellsworth, M.A.; Weaver, A.L.; Mara, K.C.; Clark, R.H.; Carey, W.A. Association of Early Inhaled Nitric Oxide With the Survival of Preterm Neonates With Pulmonary Hypoplasia. JAMA Pediatr. 2018, 172, e180761. [CrossRef] [PubMed]

35. Manja, V.; Guyatt, G.; Lakshminrusimha, S.; Jack, S.; Kirpalani, H.; Zupancic, J.A.F.; Dukhovny, D.; You, J.J.; Monteiro, S. Factors influencing decision making in neonatology: Inhaled nitric oxide in preterm infants. J. Perinatol. Off. J. Calif. Perinat. Assoc. 2018. [CrossRef] [PubMed]

36. Dixon, F.; Ziegler, D.S.; Bajuk, B.; Wright, I.; Hilder, L.; Abdel Latif, M.E.; Somanathan, A.; Oei, J.L. Treatment with nitric oxide in the neonatal intensive care unit is associated with increased risk of childhood cancer. Acta Paediatr. 2018, 107, 2092-2098. [CrossRef]

37. Vento, M.; Sanchez-Illana, A. Nitric oxide and preterm resuscitation: Some words of caution. Pediatr. Res. 2020, 87, 438-440. [CrossRef]

38. Lakshminrusimha, S.; Manja, V.; Mathew, B.; Suresh, G.K. Oxygen targeting in preterm infants: A physiological interpretation. J. Perinatol. Off. J. Calif. Perinat. Assoc. 2015, 35, 8-15. [CrossRef]

39. Alcorn, D.G.; Adamson, T.M.; Maloney, J.E.; Robinson, P.M. A morphologic and morphometric analysis of fetal lung development in the sheep. Anat. Rec. 1981, 201, 655-667. [CrossRef]

40. Eyal, F.G.; Hachey, W.E.; Curtet-Eyal, N.L.; Kellum, F.E.; Alpan, G. Effect of modulators of hypoxic pulmonary vasoconstriction on the response to inhaled nitric oxide in a neonatal model of severe pulmonary atelectasis. Semin. Perinatol. 1996, 20, 186-193. [CrossRef]

41. Booke, M.; Bradford, D.W.; Hinder, F.; Harper, D.; Brauchle, R.W.; Traber, L.D.; Traber, D.L. Effects of inhaled nitric oxide and nebulized prostacyclin on hypoxic pulmonary vasoconstriction in anesthetized sheep. Crit. Care Med. 1996, 24, $1841-1848$. [CrossRef]

42. Fike, C.D.; Hansen, T.N. The effect of alkalosis on hypoxia-induced pulmonary vasoconstriction in lungs of newborn rabbits. Pediatr. Res. 1989, 25, 383-388. [CrossRef] [PubMed]

43. Kirpalani, H.; Ratcliffe, S.J.; Keszler, M.; Davis, P.G.; Foglia, E.E.; Te Pas, A.; Fernando, M.; Chaudhary, A.; Localio, R.; van Kaam, A.H.; et al. Effect of Sustained Inflations vs Intermittent Positive Pressure Ventilation on Bronchopulmonary Dysplasia or Death Among Extremely Preterm Infants: The SAIL Randomized Clinical Trial. JAMA J. Am. Med. Assoc. 2019, 321, 1165-1175. [CrossRef] [PubMed] 